Revista de Estudios Histórico-Jurídicos

[Sección derecho romano]

XLI (Valparaíso, Chile, 2019)

[pp. 37-49]

\title{
LIBERTAD Y ESCLAVITUD EN ROMA ARCAICA
}

[Freedom and Slavery in Archaic Rome]

\author{
Carlos Amunátegui Perelló* \\ Pontificia Universidad Católica de Chile**
}

\section{RESUMEN}

El presente artículo explora la noción de libertas, especialmente mediante su comparación con el concepto de esclavitud y su surgimiento en Roma Arcaica. Las siguientes páginas tratarán del surgimiento del trabajo subordinado, de la aparición del término libertas y de la configuración del estatuto del esclavo durante el período Arcaico de la Historia de Roma.

\section{Palabras clave}

Libertas - trabajo subordinado ciudadanía.

\section{ABSTRACT}

This paper explores the notion of libertas and its comparison with the concept of slavery in Archaic Rome. The following pages will search for the origins of unfree labour in Archaic Rome, the emergence of the concept of libertas, and the configuration of the status of slavery.

\section{KEYWORDS}

Libertas - unfree labour - citizenship.

RECIBIDO el 3 de mayo de 2019 y ACEPTADO el 2 de julio de 2019

\section{INTRODUCCIÓN}

La esclavitud tiene una larga historia en la sociedad romana. Usualmente, los estudios sobre la materia han tendido a centrarse en el período que va desde la Primera Guerra Púnica hasta la Crisis del siglo III d.C., época en la cual su importancia económica y social fue máxima, llegando a calificarse a la Roma como una sociedad esclavista ${ }^{1}$. No obstante, la esclavitud, como institución económico-

* Profesor de derecho romano, Pontificia Universidad Católica de Chile.

**Este artículo es parte del proyecto Fondecyt Regular 1180022.

${ }^{1}$ Véase a propósito de este término BRADLY, Keith, Slavery and Society at Rome (Cambridge, 1994), pp. 10-29. 
social, parece considerablemente más antigua. Hay constancia de ella en la Ley de las XII Tablas² e incluso en el pasado legendario de Roma.

El presente trabajo intentará abordar el tema de la esclavitud y de la libertad en el pasado arcaico de Roma. Intentaremos rastrear el origen del trabajo subordinado en dicha sociedad, hasta donde las fuentes arqueológicas nos lo permitan, para luego establecer los orígenes del concepto de libertas y del estatuto del esclavo en Roma arcaica.

\section{LA ARQUEOLOGÍA Y EL TRABAJO SUBORDINADO}

No podemos sindicar el momento preciso en que la esclavitud se convirtió en parte de la experiencia romana. Probablemente, era un elemento intrínseco a la sociedad latina mucho antes que ningún registro histórico existiese. La primera evidencia con que contamos relativa a la existencia de trabajo subordinado en la sociedad latina viene de la arqueología. De acuerdo a la interpretación de Bietti Sestieri de los restos encontrados en la necrópolis de Osteria dell'Ossa ${ }^{3}$, los grupos funerarios más antiguos del lugar, provenientes del Período Lacial II (c.900-770 a.C.) no muestran trazas de diferenciación social entre los inhumados. Las únicas diferencias que pueden detectarse provienen del género y la edad, mas no del estatus ${ }^{4}$. Los hombres de entre 16 y 40 años de edad se ubican al centro, estando equipadas sus tumbas con material cerámico de escaso valor y puntas de lanzas en miniatura. En torno a este grupo se ubican los restos de mujeres en edad fértil, con material cerámico de idéntica naturaleza y, generalmente, husos para hilar la lana. En un círculo exterior se suelen ubicar las tumbas de los niños y ancianos, cualquiera sea su género, usualmente los primeros en el lado este, mientras que los segundos en el oeste. El material funerario en estos casos consiste fundamentalmente en restos cerámicos.

Parece interesante que, a comienzos de la etapa siguiente, el llamado Período Lacial III (c.770-740 a.C.), la introducción de diversas nuevas tecnologías provenientes del mundo Griego ${ }^{5}$ en el área de Italia central parecen haber afectado

\footnotetext{
${ }^{2}$ (Bruns) XIIT 2.1, 5.8, 6.6, 8.3, 8.14, 10.6a, 11.2a-2b.

${ }^{3}$ Bietti Sestieri, Annamria, The Iron Age community of Osteria dell'Osa. A study of sociopolitical development in central Tyrrhenian Italy (Cambridge, 1992), pp. 146-150.

${ }^{4} \mathrm{La}$ arqueóloga encargada de las excavaciones describe dos grupos principales de inhumaciones, los que muestran dos distintas tradiciones en sus entierros, el grupo norte y el sur. Cada uno de estos desarrolla distintas locaciones para sus entierros colectivos, los que corresponderían a dos o tres generaciones de individuos. De acuerdo con la evidencia encontrada, los grupos - que pueden ser confiablemente datados entorno a los siglos IX y hasta mediados del VIII a.C.- parecen diferenciar las inhumaciones de sus miembros de acuerdo a su edad (los individuos de entre 15 y 40 años en la posición central y privilegiada) y el sexo. Los bienes inhumados junto a los hombres y mujeres en esta franja de edad estarían compuestos de algunos elementos socialmente importantes (cabezas de lanzas para los hombres, husos para las mujeres) y algo de cerámica, mientras que los miembros fuera de esta franja etaria, carecerían de estos bienes privilegiados.

${ }^{5}$ Esto incluye la capacidad de leer y escribir, el torno del alfarero, el horno con diafragma, mejoras técnicas en el trabajo del bronce y el hierro y, posiblemente, la vid y la oliva. Véase
} 
los patrones de producción. Durante esta época aparecen el cultivo de la vid y la oliva, permitiendo mejorar la productividad de las tierras más altas, las que hasta entonces parecen haber estado desocupadas, a lo menos respecto a la agricultura ${ }^{6}$. De la misma manera, los asentamientos se expanden ${ }^{7}$, desarrollándose un proceso de aglutinamiento o nucleización entre diversas comunidades menores que anteriormente vivían separadas, concentrándose la población de los asentamientos más pequeños en nuevos grupos más amplios ${ }^{8}$.

Para este mismo espacio temporal, Bietti Sestieri encuentra evidencia relativa a la existencia de trabajo subordinado en Osteria dell'Ossa. El grupo funerario encontrado se trata de las tumbas 230 a 293. Este grupo parece ser el primero que ubica una pareja en su centro (las tumbas 262 y 259), las que corresponden a un hombre de edad avanzada y una mujer joven, donde la tumba del varón incluye también una espada. Las tumbas que inmediatamente los rodean son más ricas que el resto, mientras que en la periferia del grupo se ubican tumbas que no tienen bienes funerarios en absoluto'. Estas diferencias en el ajuar funerario se ampliarán en los sucesivos grupos funerarios, llegando, en el período sucesivo (c.740-640 a.C.) a aparecer conjuntos funerarios de gran riqueza, las así llamadas tumbas principescas, las que incluirán huevos de avestruz, artículos de oro y, en un caso, incluso un carro de combate completo con sus aperos.

En pocas palabras, durante la segunda mitad del siglo VIII a.C. y la primera mitad del siglo VII a.C., junto con la introducción de varias nuevas tecnologías en la producción y la expansión de los asentamientos, las distinciones sociales, al menos en los contextos funerarios, aparecen. La presencia de tumbas sin bienes sugiere la aparición de una población subordinada que habitaba junto a un grupo de individuos más ricos. Esto bien puede ser interpretado como la emergencia del trabajo subordinado.

\section{ESCLAVITUD Y TRABAJO SUBORDINADO}

En cualquier caso, la existencia de trabajo subordinado no implica la presencia de esclavitud. De hecho, existen varias formas en que los romanos de tiempos históricos reclutaron trabajadores sin recurrir a la esclavitud, siendo la más relevante el nexum. La mancipatio podía ser usada para crear un vínculo de subordinación,

al respecto: Torelli, Mario, History: Land and People, en Etruscan Life and Afterlife (Detroit, 1986), pp. 51-52; ForsYTHE, Gary, A Critical History of Early Rome, (Berkeley, 2006), p. 56.

${ }^{6}$ Para un estudio detallado relativo a los suelos y a la ocupación de la tierra desde la Edad del Bronce hasta el período Arcaico, véase: Fulminante, Francesca, Eviroment and Settlement Analysis: Investigating the Bronze and Iron Age Latium Vetus Physical and Political Landscape, en Broadening Horizons, Multidisciplinary Approaches to Landscape Study (Newcastle, 2007), pp. 152-183.

${ }^{7}$ MoreL, Jean-Paul, Early Rome and Italy, en The Cambridge Economic History of the GrecoRoman World (Cambridge, 2007), p. 493.

${ }^{8}$ Torelli, Mario, cit. (n. 5), p. 35; Cornell, Tim J., The Beginnings of Rome and Italy from the Bronze Age to the Punic Wars (c.1000-264 BC) (London y New York, 1995), p. 90.

${ }^{9}$ Bietti Sestieri, Annamria, cit. (n. 3), pp. 203 ss. 
sea a través del nexum ${ }^{10}$ o mediante la transferencia de alieni iuris en posición de dependencia al poder de otro paterfamilias. Tanto el nexi como el filii familias in mancipio debían trabajar para el adquirente ${ }^{11}$, no obstante mantener su libertad formal, sus deberes militares y ciudadanía. Su situación es descrita por las fuentes como loco servorum ${ }^{12}$, es decir, ocupando el lugar de un esclavo. Esto no significa que eran verdaderos esclavos. De hecho, sabemos que, al menos en tiempos históricos, el hijo in mancipio no podía ser maltratado, puesto que contaba con la actio iniuriarum en contra de quien detentaba poder sobre é ${ }^{13}$, pudiendo incluso obligarlo a liberarlo cuando el tiempo establecido sobreviniese ${ }^{14}$. Estas formas de reclutar fuerza de trabajo se mantuvieron vigentes hasta la República media, cuando fueron finalmente reemplazadas por la esclavitud. En dicha época, el nexum habría sido abolido por la lex poetelia papiria en el 326 a.C., mientras que la cesión de hijos no parece haber sido comúnmente utilizada para estos efectos en tiempos históricos ${ }^{15}$.

${ }^{10}$ La naturaleza del nexum es un asunto bastante debatido. La información que tenemos parece algo contradictoria. Parece ser un acto libral, esto es, que debe ser realizado a través de la solemnidad del bronce y la balanza: Fest. Verb. 165.20 Nexum est, ut ait Gallus Aelius, quodcumque per aes et libram geritur: id quod necti dicitur. Quo in genere sunt haec: testamenti factio, nexi datio, nexi liberatio. Cic. De orat. 3.159 Nam si res suum nomen et vocabulum proprium non habet...ut nexum, quod per libram agitur [...] Varr. L. 7.105 In Colace: 'nexum' Manilius scribit, omne quod per libram et aes geritur, in quo sint mancipia. Mucius, quae per aes et libram fiant ut oblige[n]tur, praeter quom mancipio de $<n>t u r$. hoc verius esse ipsum verbum ostendit, de quo qu<a>erit: nam id <a>es[t] quod obligatur per libram neque suum fit, inde nexum dictum. En todo caso, se debate si es que esto significa que el acto se realiza a través de una mancipatio o a través de algún otro medio. En las XII Tablas, la famosa disposición cum nexum faciet mancipiumque, uti lingua nuncupassit, ita ius esto [Festus Verb 173.11] es altamente debatida. Para un resumen de las ideas surgidas al respecto, véase: ST. Tomulescu, Constantin, Nexum bei Cicero, en IURA., 17 (1966), pp. 39 ss. Las principales teorías son las siguientes: Huschke propone que el nexum es simplemente una deuda contraída por aes et libram (véase HusCHKE, Philipp Eduard, Ueber das Recht des nexum und das alte römische Schuldrecht (Leipzig, 1846), seguido por BEKKer, Ernst Immanuel, Die Aktionen des röm. Privatrechts (Berlin, 1871). Una segunda teoría propone que el nexum es una auto mancipación (véase MiTTEIs, Ludwig, Ueber das Nexum, en Zeitschrift der Savigny-Stiftung für Rechtsgeschichte: Romanistische Abteilung, 21 (1901), pp. 96 ss.). A esta teoría se opusieron Lenel y Kretschmar (véase LeNEL, Otto, Das Nexum, en Zeitschrift der Savigny-Stiftung für Rechtsgeschichte / Romanistische Abteilung, 23 (1903), pp. 84 ss. y Kretschmar, Paul Gustav, Das Nexum und sein Verhältnis zum Mancipium, en Zeitschrift der Savigny-Stiftung für Rechtsgeschichte / Romanistische Abteilung, 29 (1908), pp. 227 ss.). En cualquier caso, la teoría de Mitteis es ahora dominante.

${ }^{11}$ Varr. L. 7.105 liber qui suas operas in servitutem pro pecunia quam debebat, dum solveret, nexus vocatur, ut ab aere obaeratus. hoc C. Poetelio Libone Visolo dictatore sublatum ne fieret, et omnes qui bonam copiam iurarunt, ne essent nexi, dissoluti.

${ }^{12}$ Gai 1.138

${ }^{13}$ Gai 1.141 .

${ }^{14}$ Gai 1.140 .

${ }^{15}$ De hecho, la mancipatio de los descendientes parece subsistir en las explicaciones jurídicas porque fue utilizada más tarde para satisfacer otras necesidades sociales distintas a la provisión de mano de obra. Formaba parte del procedimiento de adopción (Gai. 1.99), de la coemptio (Gai. 1.118) y de la emancipación (Gai.1.134). 
En cuanto a la esclavitud, hay algunas señalen que apuntan a una introducción temprana de tal práctica durante el período formativo de Roma. La tradición apunta a Tarquino Prisco en este sentido, toda vez que le imputa el dudoso honor de haber sido el primer rey en esclavizar a los enemigos vencidos ${ }^{16}$. De hecho, durante la monarquía tardía se realizaron obras públicas de gran envergadura, entre las que destaca la desecación del valle del Foro y la construcción de grandes edificios públicos ${ }^{17}$. Esto habría requerido una fuerza de trabajo masiva. La palabra que los romanos utilizaban para designar a los esclavos, servus, parece tener orgines etruscos, proviniendo del vocablo serve ${ }^{18}$, cuestión que constituiría un elemento que refuerza la relación entre la influencia etrusca y la esclavitud ${ }^{19}$. Incluso más llamativo resulta el que en las XII Tablas la única palabra utilizada para referirse a los esclavos sea justamente servus, y no algún otro equivalente de raigambre latino, como mancipium. Incluso más, de acuerdo a la tradición, Servio Tulio introdujo una ley que tenía por objeto otorgar la ciudadanía a los esclavos liberado ${ }^{20}$, un elemento que permanecerá como una rareza en el contexto de la Antigüedad incluso en tiempos históricos.

Otro personaje de carácter simbólico ligado a la esclavitud es Junio Bruto, el liberador de Roma y fundador de la República. A comienzos de su consulado, un esclavo denunció a los hijos de Bruto por conspirar en contra de la recién fundada República a fin de restablecer a Tarquino el Soberbio. Bruto inmediatamente los ejecutó $^{21}$ y le concedió la libertad y ciudadanía al esclavo ${ }^{22}$. Según Livio, el cónsul introdujo a través de este acto una nueva forma de liberar a los esclavos, tocándolos con la vindicta, una suerte de vara utilizada en la antigua legis actio sacramentum

${ }^{16}$ Dion. Hal. 3.49-50, 6.19-20. Véase Franciosi, Gennaro, Famiglia e persone in Roma antica (Torino, 1992), p. 208; SERRAO, Feliciano, Diritto privato economia e società nella storia di Roma (Napoli, 2006), p. 205.

${ }^{17}$ Torelli, Mario, Archaic Rome Between Latium and Etruria, en The Cambridge Ancient History, 7-2 (Cambridge, 1989), p. 37; Momigliano, Arnaldo, The Origins of Rome, en The Cambridge Ancient History, 7-2 (Cambridge, 1989), pp. 95-96; SMITH, Christopher J., Early Rome and Latium (Oxford, 1996), p. 150; EDLUND-BERRY, Ingrid, Early Rome and the Making of "Roman" Identity through Architecture and City Planning, en A Companion to the Archeology of the Roman Republic (Malden-Oxford, 2013), pp. 406-425.

${ }^{18}$ Véase: Bonfante, Giuliano, Etruscan Words in Latin, en Word, $36 / 3$ (1985), pp. 203-210; Benveniste, Émile, Le nom de l'esclave à Rome, en REL., 10 (1932), pp. 429 ss.; DE VisSCHER, Fernand, Mancipium et res mancipi, en SDHI., 2 (1936), p. 246. Existían algunas etimologías ficticias que derivaban la palabra servus de servare, salvar, toda vez que los esclavos serían cautivos salvados de la muerte, como en D.1.5.4.2-3 y D.50.16.239.1. Véase Gamauf, Richard, Slavery. Social Position and Legal Capacity, en Du Plessis, Paul; Ando, Clifford and Tuori, Kaius (eds.), The Oxford Handbook of Roman Law and Society, (Oxford, 2016), p. 384.

${ }^{19}$ Franciosi, Gennaro, Res mancipi e res nec mancipi, en Labeo, 5/3 (1959), p. 375; Franciosi, Gennaro, cit. (n. 16), p. 206; De Martino, Francesco, Clienti e condizioni materiali in Roma arcaica, en Diritto economia e società nel mondo romano (Napoli, 1997a), pp. 82-83; DE MARTINO, Francesco, Intorno all'origine della schiavitù a Roma, en Diritto economía e società nel mondo romano (Napoli, 1997), pp. 27-57.

${ }^{20}$ Dion. 4.22.4, Zonar 7.9.

${ }^{21}$ Liv. 2.5.5; Val Max. 5.8.1; Virg. Aen. 816; Dion. Hal. 5.7-8.

${ }^{22}$ Liv.2.5.8, Dion. Hal 5.13. 
in rem para reivindicar la propiedad ${ }^{23}$. Resulta, por supuesto, altamente simbólico que el creador de la República y, por tanto, libertador de Roma, sea quien introduzca un nuevo método para liberar a los esclavos, fortaleciendo el vínculo entre la libertas pública y la libertad como emancipación de una condición servil, muy en línea con el famoso comienzo de los Anales de Tácito ${ }^{24}$. Fuese como fuese, para el comienzo de la República, el trabajo servil parece común y la figura del esclavo ha aparecido en la arena socio-jurídica de Roma.

\section{ESCLAVITUD Y LIBERTAD EN LA REPÚBLICA TEMPRANA}

La palabra libertas parece tener una morfología arcaica. Sigue el patrón liberlibertas de la misma manera que vetus-vetustas, mas no el más reciente sufijo-eritas, como en prosper, prosperitas ${ }^{25}$. La palabra liber tiene un significado primario ligado al crecimiento, como en la pareja divina formada por Liber y Libera ${ }^{26}$, cuya festividad principal era la Liberalia ${ }^{27}$. En este sentido, los descendientes de un pater, aquellos que se encontraban, en cierto sentido creciendo, eran usualmente llamados liberi en las locuciones jurídicas arcaicas, como en la declaración solemne que se realizaba ante el censor respecto a que el ciudadano tenía una cónyuge liberorum quaerendorum causa ${ }^{28}$.

El paterfamilias en tiempos históricos ostentaba la potestas tanto sobre sus esclavos como sus descendientes ${ }^{29}$. Este era, en efecto, el mismo poder bajo el cual se encontraban tanto unos como otros, permitiéndole a su detentador actuar de una manera igualmente despótica respecto a ellos, ejerciendo su vita necique potestas, su poder de matar o dejar vivir. Incluso, la expresión vita necisque potestas parece ser equivalente a patria potestas en la terminología jurídica arcaica, puesto que el adoptante, al pedir a los comitia calata que autoricen la adopción de otro paterfamilias (adrogatio), preguntaba a los comitia si ellos aceptaban que el adoptado entrase bajo su poder de vida y muerte ${ }^{30}$. La única diferencia entre los descendientes -liberi-y los esclavos era que los primeros eran libres, mientras

${ }^{23}$ Gai. 4.16.

${ }^{24}$ Tac. Ann. 1.1. libertatem et consulatum L. Brutus instituit.

${ }^{25}$ BRACHET, Jean-Paul, Libertas/libertus et uetustas/uetustus: observations morphologiques et sémantiques, en Historische Sprachforschung / Historical Linguistics, 115 (2002), pp. 79-89.

${ }^{26}$ RaAflaub, Kurt, Freiheit in Athen und Rom: Ein Beispiel divergierender politischer begriffsentwicklung in der Antike, en Historische Zeitschrift, 238 (1984), p. 536; WISSOWA, Georg, Paulys Real-Encyclopädie der Classichen Altertumwissenschaft, b. 13, (Stuttgart, 1926), p. 68.

${ }^{27}$ Varro, De 1.1. 6.14; Macrob. Sat. 1.4.15.

${ }^{28}$ Val. Max. 2.1.4; Gell. 4.3.pr, 17.21.44; Vid: PÉTer, Orsolya Marta, Liberorum quaerundorum causa, en RIDA., 38 (1991), pp. 285-332.

${ }^{29}$ Gai.1.52 In potestate itaque sunt serui dominorum. quae quidem potestas iuris gentium est: nam apud omnes peraeque gentes animaduertere possumus dominis in seruos uitae necisque potestatem esse, et quodcumque per seruum adquiritur, id domino adquiritur. Gai.1.55 Item in potestate nostra sunt liberi nostri, quos iustis nuptiis procreauimus. quod ius proprium ciuium Romanorum est (fere enim nulli alii sunt homines, qui talem in filios suos habent potestatem, qualem nos habemus) idque diui Hadriani edicto, quod proposuit de his, qui sibi liberisque suis ab eo ciuitatem Romanam petebant, significatur. nec me praeterit Galatarum gentem credere in potestate parentum liberos ese.

${ }^{30}$ Aulo Gell. N.A. 5.19.9 Eius rogationis uerba haec sunt: 'Velitis, iubeatis, uti L. Valerius L. 
que los segundos no, y por ello la cualidad específica de estos descendientes fue la libertas (liber-libertas). En este sentido, a palabra libertas parece ser un desarrollo de las relaciones que se mantenían dentro del grupo familiar, designado con ella la cualidad específica de aquellos miembros que, aún estando bajo el poder del pater, no tenían una condición servil al ser sus descendientes. En las XII Tablas la palabra es usada en este sentido consistentemente ${ }^{31}$.

En cualquier caso, el vínculo entre status libertatis y ciudadanía puede haber aparecido incluso en la temprana historia jurídica de Roma. Aunque no tenemos noticia de una prohibición expresa de esclavizar a ciudadanos en las XII Tablas, algunas de las disposiciones del contexto jurídico arcaico parecen suponerla ${ }^{32}$. La más famosa de ellas proviene de las XII Tablas. Nos referimos a aquella disposición que establece la posibilidad de vender al deudor trans Tiberim en el contexto de la manus iniecto ${ }^{33}$. Parece ser que no era posible transformar a un ciudadano en esclavo dentro de los límites de la ciudad, por lo que los decenviros habrían permitido esclavizar al deudor mediante su venta fuera de la esfera de influencia de la ciudad, en el lado etrusco del Tíber. Lo mismo puede decirse el ius postliminium $^{34}$. Esta institución tenía por objetivo el retornar la libertad al ciudadano que había sido capturado y reducido a esclavitud. Si es que lograba volver a la ciudad, el adquiría nuevamente su ciudadanía ${ }^{35}$ y derechos. Aunque no sabemos cuándo el postliminium fue creado ${ }^{36}$, su contexto parece arcaico, y podría haber estado relacionado con algún tipo de prohibición de esclavizar a los ciudadanos en Roma misma, como aquélla atribuida por Dionisio a Servio Tulio ${ }^{37}$. Según Dionisio, Servio Tulio habría prohibido el ofrecer servicios personales como garantía del pago de deudas. De cualquier modo, al menos en la forma en que Dionisio parece haber entendido la disposición, ésta parece algo improbable, puesto que habría anticipado la lex poetelia papiria en casi trescientos años y sabemos que el nexum continuó siendo posible durante la República temprana y media. Creemos que tal vez la norma descrita por Dionisio pudo provenir de una disposición más sencilla que prohibiese la esclavitud de ciudadanos propiamente tal, mas no figuras que

Titio tam iure legeque filius siet, quam si ex eo patre matreque familias eius natus esset, utique ei uitae necisque in eum potestas siet, uti patri endo flio est. Haec ita, uti dixi, ita uos, Quirites, rogo'.

${ }^{31}$ Así, por ejemplo, en (Bruns) XIIT 8.3, 8.14 donde libero está contrapuesto a servo.

${ }^{32}$ Levy, Ernst, Libertas und Civitas, en Zeitschrift der Savigny-Stiftung für Rechtsgeschichte I Romanistische Abteilung, 78 (1961), pp. 142, 147.

33 (Bruns) XIIT. 3.5, Gell.20.1.46-47.

${ }^{34} \mathrm{Al}$ respecto véase: Levy, Ernst, Captibus redemptus, en Classical Philology, 38/3 (1943), pp. 159-176; Hernández-Tejero, Manuel, Aproximación histórica al origen del "ius postliminii", en Gerión, 7 (1989), pp. 53-64.

${ }^{35}$ D. 49.15 .4 [Modestinus libro tertio regularum] Eos, qui ab hostibus capiuntur vel hostibus deduntur, iure postliminii reverti antiquitus placuit. An qui hostibus deditus reversus nec a nobis receptus civis Romanus sit, inter Brutum et Scaevolam varie tractatum est: et consequens est, ut civitatem non adipiscatur.

${ }^{36}$ Kaser lo vincula con el siglo III a.C. Véase KasER, Max, Das Romische Privatrecht (München, 1971), I, pp. 290-291.

${ }^{37}$ Dion. Hal. 4.9.6-7. 
implicasen una posición subordinada como el nexum, aunque esto no pasa de ser especulación.

Fuese como fuese, en la atmósfera jurídica del siglo $\mathrm{V}$ a.C. en el área mediterránea, el problema de la reducción a la esclavitud de ciudadanos era una cuestión altamente debatida. De hecho, durante el siglo precedente, Solón la había prohibido en $A_{t e n a s}{ }^{38}$. Los romanos solían vincular las ideas jurídicas griegas a las instituciones de Roma temprana, algo que se ilustraba con diversas historias que otorgaban orígenes griegos a las XII Tablas, como la famosa embajada a Atenas ${ }^{39}$ o la supuesta participación del filósofo Hermodoro en su diseño ${ }^{40}$. Aunque estas leyendas no sean relatos históricos verificables, no parece dudoso que sí existió una real influencia griega en las ideas decenvirales relativas a la legislación ${ }^{41}$. Los principales argumentos en la materia son la presencia de palabras griegas en las XII Tablas y algunas de sus disposiciones que parecen imitar la más temprana legislación griega, como la prohibición de enterrar bienes junto al fallecido. En esta misma línea, la posible inclusión de disposiciones que favorezcan la libertad podría provenir de este mismo ambiente filo-heleno. De acuerdo a las fuentes jurídicas, las XII Tablas sí contenían el principio de favor libertatis ${ }^{42}$, esto es, la idea de favorecer la causa de la libertad en los procesos judiciales ${ }^{43}$. Gayo ${ }^{44}$ apunta que al servirse de la legis actio sacramentum in rem, si el bien reclamado era la libertad del esclavo aparente, la apuesta sacramental realizada por los litigantes

\footnotetext{
${ }^{38}$ Véase Vamvoukos, Athanassios, Fundamental Freedoms in Athens of the Fifth Century, en RIDA., 26 (1979), pp. 89-124; Karavites, Peter, Eleutheria and Autonomia in Fifth Century Interstate Relationships, en RIDA., 28 (1982), pp. 145-162.

${ }^{39}$ Liv. 3.31 .

${ }^{40}$ D.1.2.2.3-4; Plin., HN 34.21; Strab. 14.1.25, p.642c

${ }^{41}$ WIEACKER, Franz, Solon und die XII Tafeln, en Studi in onore di Edoardo Volterra, (Milano, 1971), III, pp. 757-784; WIEACKER, Franz, Zwolftafelprobleme, en RIDA., 3 (1956), pp. 456-491; Ferenczy, Endre, La legge delle XII Tavole e le codificazioni greche, en Sodalitas. Scritti in onore di Antonio Guarino (Napoli, 1984), IV, pp. 2001-2012; SteInberG, Michael, The Twelve Tables and Their Origins: An Eighteenth-Century Debate, en Journal of the History of Ideas 43/3 (1982), pp. 379-396; Toher, Mark, The Tenth Table and the Conflict of the Orders, en RaAflaub, Kurt A. (ed.), Social Struggles in Archaic Rome. New Prespectives on the Conflict of the Orders, (Oxford, 2005), pp. 268-292; Cornell, Tim J., cit. (n. 8), p. 274; Forsythe, Gary, cit. (n. 5), p. 210; Bauman, Richard A., The interface of Greek and Roman Law, en RIDA. 43 (1996), pp. 39-62.

${ }^{42}$ Aunque la escuela hipercrítica puso en duda su autenticidad (véase AlBERTARIO, Emilio, Schiavitù e favor libertatis in Studi di dirito Romano, Milano, 1933, I, pp. 61-77), hoy en día hay pocas dudas sobre la autenticidad del fragmento, especialmente porque Gayo (Gai. 4.14) da constancia del mismo. Véanse al respecto: ANKUM, Hans, L'expression favor libertatis dans les travaux des juristes classiques romains, en LINARES, José Luis et al. (eds.) Liber Amicorum Juan Miquel. Estudios romanísticos con motivo de su emeritazgo, (Barcelona, 2006), p. 47; CASTELLO, Carlo, Humanitas e favor libertatis nel I secolo, en Sodalitas. Scritti in onore di Antonio Guarino, (Napoli, 1984), V, pp. 2175-2189; RicCOBONO, Salvatore, L'idea di humanitas come fonte di progresso del diritto, en Studi in onore di Biondo Biondi, (Milano, 1965), II, p. 591; IMBERT, Jean, Favor libertatis, en RHD., 27 (1949), pp. 274-279; WuBBE, Felix B. J., Humanitas de Justinien, en Tijdschrift voor Rechtsgeschiedenis, 58 (1990), p. 253.

${ }^{43}$ Riccobono, Salvatore, cit. (n. 43), p. 591; AnKum, Hans, cit. (n. 43), pp. 47-48; BradLey, Keith, cit. (n.1), p. 162.

${ }^{44}$ Gai. 4.14
} 
sería de cincuenta ases, cualquiera que fuese el valor real del aparente esclavo, a fin de favorecer las vindicationes in libertatem.

La existencia de un estado semi-servil para los deudores reservó la verdadera esclavitud sólo para los extranjeros y permitió su prohibición formal para los ciudadanos ${ }^{45}$. Aunque ellos podían aún ser objeto de trabajos forzados si no cumplían ciertas deudas garantizadas con nexum, ellos no se transformarían en verdaderos esclavos dentro del territorio romano. De hecho, la esclavitud y la ciudadanía se convirtieron en dos polos opuestos, donde la liberación de un esclavo lo transformaba en ciudadano. Hay cierto debate respecto a la antigüedad de esta última institución ${ }^{46}$, aunque las fuentes apuntan al período Arcaico $^{47}$. La esclavitud era, en cierto sentido, equivalente a la muerte ${ }^{48}$-servitutem mortalitati fere comparamus ${ }^{49}$ - por lo que todo origen étnico previo a la esclavitud se perdía con ella ${ }^{50}$. En palabras de Volterra ${ }^{51}$, durante el período Arcaico no se puede ser libre sin tener una ciudadanía, por lo que la única alternativa que quedaba era dar al esclavo manumitido la ciudadanía romana ${ }^{52}$. De hecho, todas las manumisiones formales implicaban un acto público ${ }^{53}$, toda vez que el testamento requería de la aprobación de los comitia, la vindicta necesitaba la intervención del magistrado y el censo la participación del censor. Por tanto, la manumisión no era un acto privado y su naturaleza pública permitía la generación de consecuencias de carácter público, esto es, la concesión de ciudadanía.

Finalmente, durante el último tercio del siglo IV a.C., con la aprobación de la lex poetelia papiria, el nexum fue formalmente abolido. Por tanto, para todo el período central de la historia de Roma, la esclavitud se convertirá en la forma más importante para asegurar la presencia de trabajo subordinado. Poco después,

${ }^{45}$ En palabras de Widemann: "Solon's attempt to prevent political discontent in Attica, and the pressure witch Roman peasant-soldiers were able to exert upon an elite which needed them to wage war, meant that for particular (and quite separate) reasons neither Athenians nor Romans accepted that a citizen who fell into debt should formally lose his Independence to another. Hence the enslaving of outsiders (already attested by our earliest sources, Homer and Hesiod) became much more economically significant tan it had earlier been and continued to be in those other areas of the Greek and Roman world which continued to recognise semi-servile statuses". WIEDEMANN, Thomas, Greek \& Roman Slavery (London and New York, 1994), p. 2.

${ }^{46}$ Véase Daube, David, Two Early Patterns of Manumission, en The Journal of Roman Studies, 36 (1946), pp. 57-75.

${ }^{47}$ Ya hemos mencionado la disposición atribuida a Servio Tulio en la materia (Dion. 4.22.4, Zonar 7.9). La historia relativa a Bruto también está ligada a ella (Liv.2.5.8, Dion. Hal 5.13).

${ }^{48}$ Bradley, Keith, cit. (n.1), p. 25; Giltaij, Jacob y Tuori, Kaius, Human Rights in Antiquity? Revisiting Anachronism and Roman Law, en Slotte, Pamela (ed.), Revisiting the Origins of Human Rights, (Cambridge, 2015), p. 45; Gamauf, Richard, Slavery. Social Position and Legal Capacity, en Du Plessis, Paul; Ando, Clifford y Tuori, Kaius (eds.) en The Oxford Handbook of Roman Law and Society, (Oxford, 2016), p. 384.

${ }^{49}$ D.50.17.209, Ulpianus libro quarto ad legem Iuliam et Papiam.

${ }^{50}$ Joshel, Sandra R., Slavery in the Roman World (Cambridge, 2010), p. 38.

${ }^{51}$ Volterra, Edoardo, Manomissione e cittadinanza, en Talamanca, Mario (ed.), Scritti Giuridici, (Napoli, 1991), II, pp. 395-416.

${ }^{52}$ En palabras de Levy: Keine “civitas” ohne “libertas”. Levy, Ernst, cit. (n. 34).

${ }^{53}$ Arena, Valentina, Libertas and the Practice of Politics in the Late Roman Republic (Cambridge, 2012), p. 19. Véase Gai 1.17. 
el Templo de Libertas fue erigido por Sempronio Graco dando una dimensión cultual a esta nueva configuración social ${ }^{54}$.

\section{CONCLUSIONES}

El presente estudio elabora algunas conclusiones en torno al concepto de libertas y de su contracara, la esclavitud en el período Arcaico de la historia jurídica de Roma. Al respecto, su principal objetivo es analizar, hasta donde nos es posible, el surgimiento del concepto de libertas en la historia romana y la configuración del estatuto de su opuesto, la esclavitud. Pensamos que el trabajo forzado y subordinado es antiquísimo en la sociedad lacial, probablemente incluso previo o simultáneo a la formación misma de la ciudad. La evidencia arqueológica parece apuntar en esa dirección, aunque naturalmente es difícil llegar a conclusiones seguras en la materia. Ahora bien, mientras que el trabajo subordinado es antiquísimo, existe una pléyade de evidencias que parecen apuntar a que la esclavitud formal habría aparecido en Roma bajo la influencia etrusca. La tradición convierte a Tarquino Prisco en el primer rey que reduzca a la esclavitud a los ejércitos vencidos y la etimología de la palabra servus parece apuntar en la misma dirección. Ahora bien, la voz libertad, en cambio, parece emerger de las relaciones de familia, como la cualidad fundamental que distingue a los descendientes del pater respecto a otros sujetos que se encuentran sometidos a su potestas.

Creemos que existió en el derecho arcaico una disposición que denegaba la posibilidad de esclavizar a los ciudadanos dentro de la ciudad de Roma, la cual parece estar implicada en otras disposiciones que conocemos mucho mejor, como la necesidad de vender al otro lado del Tíber a los deudores de resultas de la aplicación de la manus iniectio, o de la posibilidad de recobrar la ciudadanía al esclavo que pisase su territorio. Estas conjeturas tienen por base el auge del movimiento plebeyo y la influencia de las ideas socio-jurídicas griegas en el ambiente intelectual de Roma arcaica. Finalmente, la prohibición de las antiguas formas de trabajo subordinado, como el nexum, terminó por construir una oposición entre la condición de ciudadano y la de esclavo, a fines del período Arcaico. Durante el período Central, la ciudadanía y su opuesto, la esclavitud, serán los cimientos sobre los que se construya el edificio económico del capitalismo agrario romano. Los intereses de ambos grupos serán contrapuestos, lo cual explica, hasta cierto punto, la falta de solidaridad entre ellos. Aunque un ciudadano fuese pobre, se encontraba separado por barreras jurídicas y sociales de la condición del esclavo, hasta el punto de oponerse activamente y celebrar el castigo de los esclavos fugitivos y rebeldes en los movimientos insurreccionales de comienzos del siglo I a.C. bajo la égida de Espartaco.

\footnotetext{
${ }^{54}$ Wissowa, Georg, cit. (n. 26), pp. 101-103; Elm von Den Osten, Dorothee, The Cult of the Goddess "Libertas" in Rome and its Reflection in Ovid's Poetry and Tibullan Love Elegy, en Vergilius, 52 (2006), pp. 32-44; SPRINGER, Lawrence A., The Temple of Libertas on the Aventine, en The Classical Journal, 45/8 (1950), pp. 390-391; KoORTBOJIAN, Michael, A Painted Exemplum at Rome's Temple of Liberty, en The Journal of Roman Studies, 92, pp. 33-48.
} 
La condición de esclavo y ciudadano volverá a aproximarse durante el Bajo Imperio, pero esto es materia de un estudio aparte.

Bibliografía

Albertario, Emilio, Schiavitù e favor libertatis in Studi di dirito Romano (Milano, 1933), I, pp. 61-77.

AnKUm, Hans, L'expression favor libertatis dans les travaux des juristes classiques romains, en Linares, José Luis et al. (eds.) Liber Amicorum Juan Miquel. Estudios romanisticos con motivo de su emeritazgo, (Barcelona, 2006).

Arena, Valentina, Libertas and the Practice of Politics in the Late Roman Republic (Cambridge, 2012).

Bauman, Richard A., The interface of Greek and Roman Law, en RIDA., 43 (1996), pp. 39-62.

BekKer, Ernst Immanuel, Die Aktionen des röm. Privatrechts (Berlin, 1871).

Benveniste, Émile, Le nom de l'esclave à Rome, en REL., 10 (1932).

Bietti Sestieri, Annamria, The Iron Age community of Osteria dell'Osa. A study of socio-political development in central Tyrrhenian Italy (Cambridge, 1992).

Bonfante, Giuliano, Etruscan Words in Latin, en Word 36/3 (1985), pp. 203-210.

BRACHET, Jean-Paul, Libertas/libertus et uetustas/uetustus: observations morphologiques et sémantiques, en Historische Sprachforschung / Historical Linguistics, 115 (2002), pp. $79-89$.

Bradly, Keith, Slavery and Society at Rome (Cambridge, 1994).

CASTEllo, Carlo, Humanitas e favor libertatis nel I secolo, en Sodalitas. Scritti in onore di Antonio Guarino, (Napoli, 1984), V., pp. 2175-2189.

Cornell, Tim J., The Beginnings of Rome and Italy from the Bronze Age to the Punic Wars (c.1000-264 BC) (London y New York, 1995).

Daube, David, Two Early Patterns of Manumission, en The Journal of Roman Studies, 36 (1946), pp. 57-75.

De Martino, Francesco, Clienti e condizioni materiali in Roma arcaica, en Diritto economia e società nel mondo romano, (Napoli, 1997).

- Intorno all'origine della schiavitù a Roma, en Diritto economía e società nel mondo romano, (Napoli, 1997).

De VISSCHER, F., Mancipium et res mancipi, en SDHI., 2 (1936).

Edlund-Berry, Ingrid, Early Rome and the Making of "Roman" Identity through Architecture and City Planning, en A Companion to the Archeology of the Roman Republic (Malden-Oxford, 2013), pp. 406-425.

Elm von Den Osten, Dorothee, The Cult of the Goddess "Libertas" in Rome and its Reflection in Ovid's Poetry and Tibullan Love Elegy, en Vergilius, 52 (2006), pp. 32-44.

Ferenczy, Endre, La legge delle XII Tavole e le codificazioni greche, en Sodalitas. Scritti in onore di Antonio Guarino, (Napoli, 1984), IV, pp. 2001-2012.

Fonsythe, Gary, A Critical History of Early Rome (Berkeley, 2006).

Franciosi, Gennaro, Res mancipi e res nec mancipi, en Labeo, 5/3 (1959).

- Famiglia e persone in Roma antica (Torino, 1992).

Fulminante, Francesca, Eviroment and Settlement Analysis: Investigating the Bronze and Iron Age Latium Vetus Physical and Political Landscape, en Broadening Horizons, Multidisciplinary Approaches to Landscape Study (Newcastle, 2007), pp. 152-183. 
Gamauf, Richard, Slavery. Social Position and Legal Capacity, en Du Plessis, Paul; Ando, Clifford and Tuori, Kaius (eds.), en The Oxford Handbook of Roman Law and Society, (Oxford, 2016).

Giltaij Jacob y Tuori, Kaius, Human Rights in Antiquity? Revisiting Anachronism and Roman Law, en Slotte, Pamela (ed.) Revisiting the Origins of Human Rights, (Cambridge, 2015).

Hernández-Tejero, Manuel, Aproximación histórica al origen del "ius postliminii", en Gerión, 7 (1989), pp. 53-64.

HuschKe, Philipp Eduard, Ueber das Recht des nexum und das alte römische Schuldrecht (Leipzig, 1846).

IMBERT, Jean, Favor libertatis, en RHD., 27 (1949), pp. 274-279.

Joshel, Sandra R., Slavery in the Roman World (Cambridge, 2010).

Karavites, Peter, Eleutheria and Autonomia in Fifth Century Interstate Relationships, en RIDA., 28 (1982), pp. 145-162.

KaSer, Max, Das Romische Privatrecht (München, 1971), I.

Koortbojian, Michael, A Painted Exemplum at Rome's Temple of Liberty, en The Journal of Roman Studies, 92, pp. 33-48.

Kretschmar, Paul Gustav, Das Nexum und sein Verhältnis zum Mancipium, en Zeitschrift der Savigny-Stiftung für Rechtsgeschichte / Romanistische Abteilung, 29 (1908).

Lenel, Otto, Das Nexum, en Zeitschrift der Savigny-Stiftung für Rechtsgeschichte I Romanistische Abteilung, 23 (1903).

Levy, Ernst, Captibus redemptus, en Classical Philology, 38/3 (1943), pp. 159-176.

- Libertas und Civitas, en Zeitschrift der Savigny-Stiftung für Rechtsgeschichte : Romanistische Abteilung, 78 (1961).

MitteIs, Ludwig, Ueber das Nexum, en Zeitschrift der Savigny-Stiftung für Rechtsgeschichte: Romanistische Abteilung, 21 (1901).

Morel, Jean-Paul, Early Rome and Italy, en The Cambridge Economic History of the Greco-Roman World (Cambridge, 2007).

Momigliano, Arnaldo, The Origins of Rome, en The Cambridge Ancient History, 7/2 (Cambridge, 1989).

PÉTer, Orsolya Marta, Liberorum quaerundorum causa, en RIDA., 38 (1991), pp. 285-332.

RaAflaub, Kurt, Freiheit in Athen und Rom: Ein Beispiel divergierender politischer begriffsentwicklung in der Antike, en Historische Zeitschrift, 238 (1984).

Riccobono, Salvatore, L'idea di humanitas come fonte di progresso del diritto, en Studi in onore di Biondo Biondi, (Milano, 1965), II.

Serrao, Feliciano, Diritto privato economia e società nella storia di Roma (Napoli, 2006).

SмiтH, Christopher J., Early Rome and Latium (Oxford, 1996).

Springer, Lawrence A., The Temple of Libertas on the Aventine, en The Classical Journal 45/8 (1950).

SteInberg, Michael, The Twelve Tables and Their Origins: An Eighteenth-Century Debate, en Journal of the History of Ideas, 43/3 (1982), pp. 379-396.

St. Tomulescu, Constantin, Nexum bei Cicero, en IURA., 17 (1966).

Toher, Mark, The Tenth Table and the Conflict of the Orders, en RaAflaub, Kurt A. (ed.), Social Struggles in Archaic Rome. New Prespectives on the Conflict of the Orders, (Oxford, 2005), pp. 268-292. 
Torelli, Mario, History: Land and People, en Etruscan Life and Afterlife (Detroit, 1986). - Archaic Rome Between Latium and Etruria, en The Cambridge Ancient History, 7/2 (Cambridge, 1989).

Vamvoukos, Athanassios, Fundamental Freedoms in Athens of the Fifth Century, en RIDA., 26 (1979), pp. 89-124.

Volterra, Edoardo, Manomissione e cittadinanza, en Talamanca, Mario (ed), Scritti Giuridici, (Napoli, 1991), II, pp. 395-416.

WIEACKER, Franz, Zwolftafelprobleme, en RIDA., 3 (1956), pp. 456-491.

- Solon und die XII Tafeln, en Studi in onore di Edoardo Volterra, (Milan, 1971), III, pp. 757-784.

Wiedemann, Thomas, Greek \& Roman Slavery (London and New York, 1994).

Wissowa, Georg, Paulys Real-Encyclopädie der Classichen Altertumwissenschaft, b. 13, (Stuttgart, 1926).

Wubbe, Felix B. J., Humanitas de Justinien, en Tijdschrift voor Rechtsgeschiedenis, 58 (1990). 